\title{
Risks of Abnormally Hot Days for the Population of Baku and Assessment of Efficiency of Possible Adaptation Actions
}

Taghiyeva UR ${ }^{\star}$, Hasanov MS, Ahmadova JN, Mammadova AF and Ahmadova QB

Institute of Geography, Azerbaijan National Academy of Sciences, Azerbaijan

"Corresponding author: Taghiyeva UR, Institute of Geography, Azerbaijan National Academy of Sciences, Azerbaijan, Tel: +994502551936; E-mail: umayrataghiyeva@gmail.com

Received date: March 13, 2018; Accepted date: March 28, 2018; Published date: March 31, 2018

Copyright: ( 2018 Taghiyeva, et al. This is an open-access article distributed under the terms of the Creative Commons Attribution License, which permits unrestricted use, distribution, and reproduction in any medium, provided the original author and source are credited.

\begin{abstract}
The researchers conducted in the field of assessment of how climate change will alter human health risks is essential for preventing climate-related morbidity and mortality. The sensitiveness of people against unfavorable meteorological conditions with increase of continuation and repeating anomalous and dangerous hydro meteorological events was raised. For that reason provision of population and relevant organizations with results of researches may contribute to implementation of adaptation measures and reduce of possible risks connected with climate changes. In article the dependence between calls of ambulance and the maximum daily temperature is considered. The dependence between air temperature in summer months and population mortality is revealed.
\end{abstract}

Keywords: Climate change; Meteo-vulnerability; Human health; Sun stroke; Calls of ambulance; Mortality cases

\section{Introduction}

The relevance and urgency of this matter increased further in connection with seditions occurred with modern climatic changes. The people who had weakened organism, complicated diseases as well as suffering from some chronicle diseases (pulmonary organs, cardiovascular, cerebral systems and etc. diseases) are more vulnerable to climate-air conditions and its changes. The people always are subjected to impact of various climatic factors. The genetic adaptation of human organism to atmospheric status may cause changes of many physiological functions. The prophylaxis of diseases is most important factor in protection of human health. Either atmosphere or human organism is very complex system. Famous mathematician Van Newman noted that the human being is most complex system, for complexity the atmosphere comes after it. The numerous studies carried out in bio-meteorology field show that the atmospheric processes have impact on human health [1]. It is to be noted that the researches in this field are purposeful to carry out in view of local regional climatic features, pre-determined specific illnesses and vulnerable groups.

\section{Method}

The results of long term scientific researchers conducted at the Institute of Geography of the Academy of Sciences of Azerbaijan were used widely in this research and also assessed recent international publications for climate change and health research. We used data on research priority areas, micrometeorological information, health fields [2].

The climate of Baku city, located at subtropical zone is mild in winter, dry and hot in summer. Baku and Apsheron gets rich radiation throughout the year. The annual amount of total radiation is 132.9 $\mathrm{cal} / \mathrm{cm}^{2}$. Throughout the year local atmospheric circulation processes in most cases, mainly in summer months, dominates other processes. In summer months the dominance of low gradient atmospheric pressure causes stagnancy in air, the continuation of "hot air waves" and repetition becomes more [3]. The impact of air circulation processes as the thunder forming factor is connected with first of all with passing of atmospheric fronts, strong winds like khazri and gilavar, entry cold air masses in area, etc processes. Although it have less impact on healthy people but in risk group people with weak health andill persons it may worsen the general mood and even lead to meteopathic reactions. The observations made, analysis of ambulance callings show that the urban population, elders and children have more meteo-vulnerability [4].

The results of researches conducted in this area to be adapted either to short term or long term changes the additional resistance is required from human organism [5].The most authors evaluate the meteotropic reactions as disadaption. Meteotropic reactions usually occur simultaneously of change of meteorological conditions or little earlier of process. The complex researches conducted on biometeorology and bioclimatic studies show that the factors that directly affect the human health like air temperature, atmospheric pressure, air humidity, wind speed and direction have a particular role [6].

The air temperature is considered as most important among the mentioned meteopathic factors. Changing of heat regime leads to change of heat exchange of human organism with environment. Human being is impacted exact temperature change along with sharp changes of temperature. The daily changing of average daily temperature of weather if is up to $20^{\circ} \mathrm{C}$ it is estimated as indifferent, $2-40^{\circ} \mathrm{C}$ changes as passage, $5-60^{\circ} \mathrm{C}$ changing as sensible, changes over $60^{\circ} \mathrm{C}$ as sharp changes. The comfortable temperature conception is different for geographical location, altitude, current climatic conditions and even for separate individuals [7]. The researches show that for hot period of year the comfortable condition on Apsheron peninsula may be accepted as air temperature $24-280^{\circ} \mathrm{C}$.

In summer month's high temperature of air and in some cases high humidity further complicate the situation. As the atmospheric 
Citation: Taghiyeva UR, Hasanov MS, Ahmadova JN, Mammadova AF, Ahmadova QB (2018) Risks of Abnormally Hot Days for the Population of Baku and Assessment of Efficiency of Possible Adaptation Actions. J Climatol Weather Forecasting 6: 228. doi: $10.4172 / 2332-2594.1000228$

Page 2 of 3

processes are non-linear processes the links between two very complex systems in biometeorlogical studies atmosphere and human organism are non-linear, too.

Weather conditions are not reasons, but it pushes for acute meteotropic reactions, as meteotrophy is one of the features of human body. From point of view of reaction of organisms, in general cyclones are considered as unfavorable, anti-cyclones as mainly favorable. But meteotrophy depends on individual pathologic, local climate factors, as well as seasons of year. The risky weather type is sharp variance of air temperature from climatic norm, continuous sharp heat, change of oxygen amount over $10 \mathrm{~g} / \mathrm{m}^{3}$, weak wind in hot period of year or wind with speed of $1-2 \mathrm{~m} / \mathrm{ps}$, stuffy air at result of relative humidity in conditions of stagnant weather conditions at the background of high temperature and other such factors are considered particularly unfavorable for population, risky for Meteo vulnerable people [6]. Apparently in Figure 1 between in average monthly the air temperature and exports of ambulance it is traced connection, namely with increase in average monthly air temperature addresses to emergency medical service become frequent. If in 2010-2016 in June at average monthly air temperature $25,00 \mathrm{C}$ the number of addresses is 47067 , then in August at $27,70^{\circ} \mathrm{C}$ this number increases up to 51062 cases

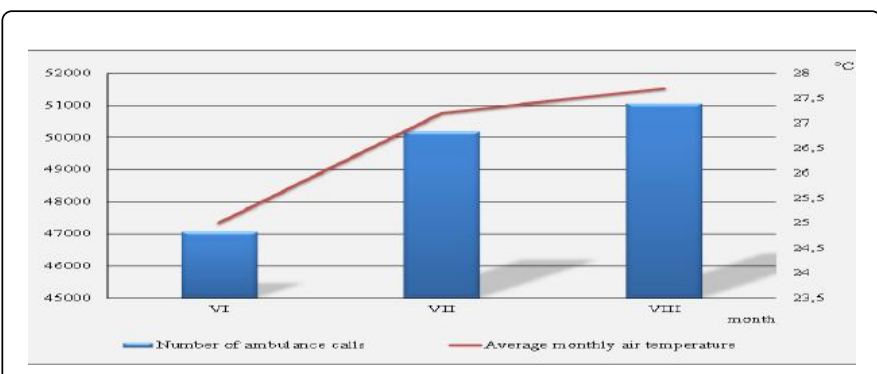

Figure 1: Average monthly air temperature in summer months and number of calls of ambulance.

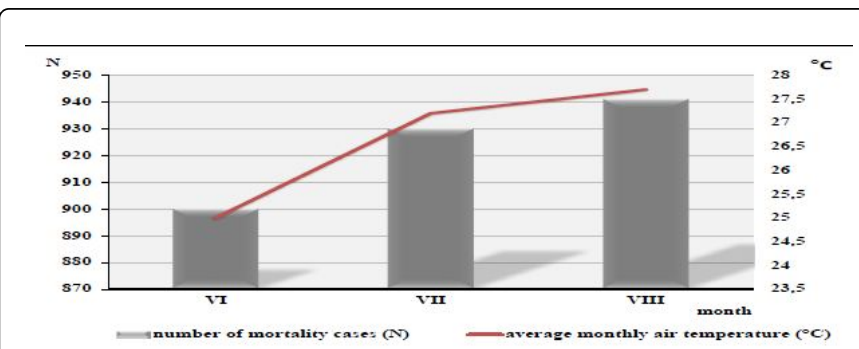

Figure 2: Average monthly air temperature and number of mortality cases.

Apparently from (Figure 2) in the summer in August at higher temperature condition also the bigger number of mortality among the population, than in June is recorded. At anomalous hot summer days to stay for longer time under the sun in open air may cause sun stroke and hot stroke and complication of some diseases. The conducted researches show that the increase in number of anomalous hot days and its continuation in summer months is observed [8].

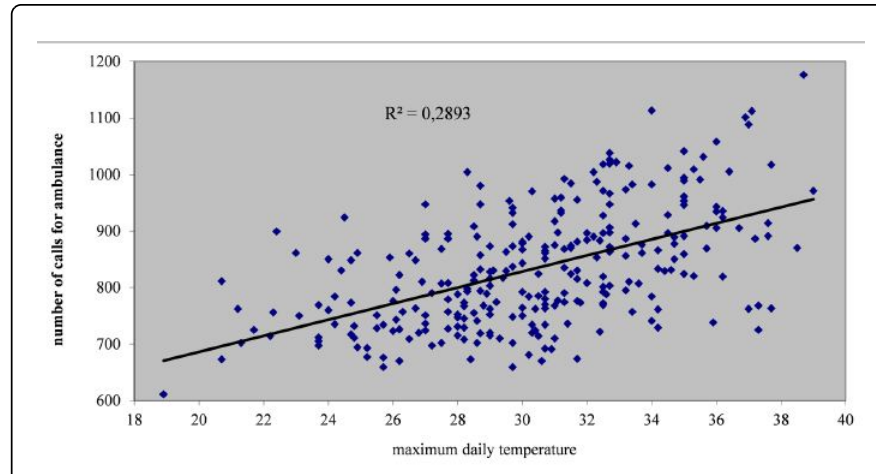

Figure 3: Dependence between calls of ambulance and the maximum daily.

\section{Temperature}

For assessment of influence of high temperatures of air in the summer on the population the interrelation between number of daily calls of emergency medical service in the city of Baku and daily maximum air temperature was analysed. In the hottest years the positive correlation increases (Figure 3). Thus, during 1961-1990 the number of days with temperature of 350 and over was in average 3 days, but during 2001-2010 years, noted as the hottest decade during all instrumental observations by the World Meteorological Organization the number of such days in Baku city increased more than 5 times and reached $16[9,10]$. As the number of days with temperature of 350 and higher is more, the number of calls for ambulance and number of those addressed with sun stroke diagnosis increases, too (Figure 4).

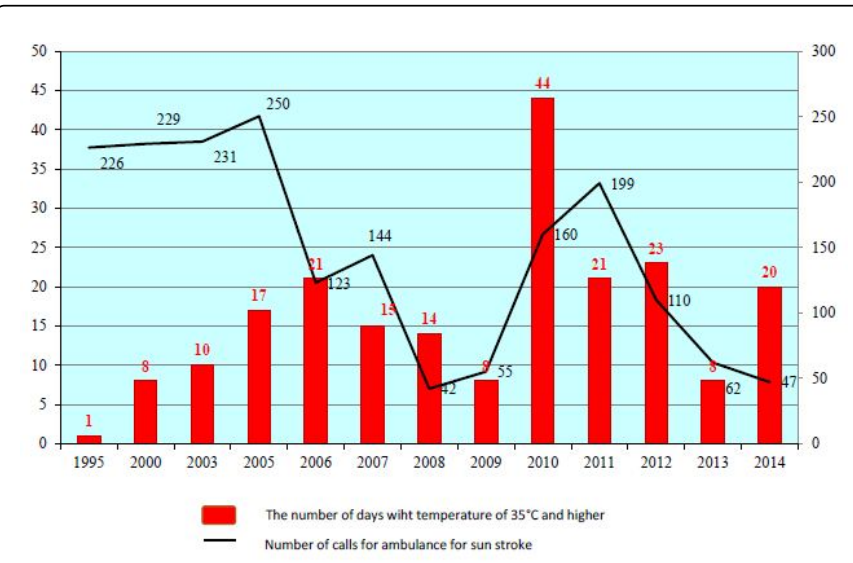

Figure 4: The number of days with temperature of $350^{\circ} \mathrm{C}$ and higher and number of calls for ambulance for sun stroke.

Apparently from the (Figure 4) if in the period of 1995-2005 about increase in number of days with $\mathrm{T} \max \geq 350$ the number of calls for ambulance for sun stroke increases too. Since 2006 national hydro meteorological service along with daily forecasts medicometeorological forecasts and warnings of adverse weather conditions for meteo-vulnerable people take root. Storm notifications about the expected of heat waves are transferred to the media from two-three day advance time. Public institutions also obtain this information. 
Citation: Taghiyeva UR, Hasanov MS, Ahmadova JN, Mammadova AF, Ahmadova QB (2018) Risks of Abnormally Hot Days for the Population of Baku and Assessment of Efficiency of Possible Adaptation Actions. J Climatol Weather Forecasting 6: 228. doi: $10.4172 / 2332-2594.1000228$

Page 3 of 3

Apparently from the (Figure 1 and 2). In the last decades, despite increase of abnormal and hot days and increase in intensity and duration of heat waves, number of calls for ambulance for sun stroke didn't increase, and on the contrary considerably decreased. For example, if in the $2005^{\text {th }}$ year 17 days with temperature of $350^{\circ} \mathrm{C}$ and higher were registered, there were 250 number of calls for ambulance for sun stroke. At the same time about the hottest year for the entire period of meteorological observations 2010 at 44 days with temperature of $350^{\circ} \mathrm{C}$ and higher, there were only 160 number of calls for ambulance for sun stroke that is almost twice less in comparison with the period when the population and the relevant structures didn't receive storm notifications about the expected adverse conditions. It can be connected with improvement of the warning system of the population and to consider as the successful example died adaptations to climatic changes.

\section{Conclusion}

The information on meteorology and climate occupies very important place for human health. As weather and climate impacts on daily life on people at condition of change able atmospheric processes the man should be more careful to own health. In general, the solution of problems of impact of environment on human health and his/her welfare is a matter of great social significance. Therefore study of connections between atmosphere and human organism, increasing of knowledge with joint efforts of both medical staff and meteorologists serves first of all to increasing their potential for their adaptation to unfavorable weather conditions by informing the population.

\section{References}

1. Tkachuk SV. Overview of the indices of the degree of comfort in weather conditions and their relationship to mortality rates.
2. Eyubov AD, Gadzhiev GY (1987) Biometeorological assessment of the air environment under Khazri and gilyavar on the Absheron Peninsula. Proceedings of the Academy of Sciences of Azerbaijan. SSR, a series of Earth Sciences 3: 44-50.

3. Taghiyeva UR, Ahmadova JN (2015) Methodical manual for preparation of medical-meteorological forecasts Baku pp: 44.

4. Mc. Geehin MA, Mirabelli M (2001) The potential impacts of climate variability and change on temperature-related morbidity and mortality in the United States Environmental Health Perspectives 109: 185-189.

5. Ragimov HSh, Ahmadova JN, Taghiyeva UR (2014) Assessment of the impact of expected climate changes on the population of Azerbaijan and possible adaptation to them. International Conference Adapt to them Climate.

6. Akhmedova JN, Almaty (2014) Influence of heat periods on the health of the population of the Absheron peninsula. Therapeutic Herald pp: 154-156.

7. Golovina EG, Rusanov VI (1993) Some questions of biometeorology. St. Petersburg.pp: 88.

8. Fouillet A, Rey G, Laurent F, Pavillon G, Bellec S, et al. (2006) Excess mortality related to the August 2003 heat wave in France. Int Arch Occup Environ Health 80: 16-24.

9. Kasymov MS (1985) Sultry weather and oxygen regime of the atmosphere on the example of the coastal zone of Azerbaijan. Vopr Spa, physiotherapy, and lech physical culture 3: 37-89.

10. Ayyubov AK, Musayev ZF, Kerimov AA, Hajiyev GH, Mustafayeva VT (1997) Climate and human health of Baku and Absheron peninsula. Baku, Azerneshr pp: 126. 